\title{
Impacts of different intensities of exercise on inflammation and hypoxia markers in low altitude
}

Fatih Baygutalp ${ }^{1 *}$, Yusuf Buzdağ $\iota^{2}$, Murat Ozan ${ }^{3}$, Mitat Koz ${ }^{4}$, Nurcan Kılıç Baygutalp ${ }^{5}$ and Gökhan Atasever ${ }^{6}$

This study will be presented as an oral presentation in Eastern Black Sea Rheumatology Days on 18-19

December 2021 in Turkey.

\begin{abstract}
Background: This study aims to determine and compare the effects of exercise modalities with different intensities on the secretion of key inflammation and hypoxia markers in amateur athletes.

Methods: Twenty-three athletes with a mean age of 20.1 years, living at low altitude $(1850 \mathrm{~m})$ participated in this study. The participants' maximal oxygen consumption values $\left(\mathrm{VO}_{2}\right.$ max) were determined with an incremental cycle exercise test as $54.15 \pm 6.14 \mathrm{~mL} \mathrm{~kg} \mathrm{~min}{ }^{-1}$. Athletes performed four protocols: at rest, $50 \% \mathrm{VO}_{2} \max , 75 \% \mathrm{VO}_{2} \max$ and $100 \% \mathrm{VO}_{2} \max$ (until exhaustion) with one-week intervals. 50\% $\mathrm{VO}_{2}$ max, $75 \% \mathrm{VO}_{2}$ max sessions were performed continuously for 30 min on a bicycle ergometer and $100 \% \mathrm{VO}_{2}$ max session was performed by cycling until exhaustion. Blood samples were obtained at rest and immediately after each exercise session. Serum tumor necrosis factor alpha (TNF-a), C-reactive protein (CRP), interleukin-10 (IL-10), and hypoxia inducible factor-1 alpha (HIF-1a) levels were measured.
\end{abstract}

Results: There were significant differences in serum TNF-a levels in $75 \% \mathrm{VO}_{2}$ max and $100 \% \mathrm{VO}_{2}$ max sessions ( $489.03 \pm 368.37$ and $472.70 \pm 365.21 \mathrm{ng} / \mathrm{L}$, respectively) compared to rest conditions ( $331.65 \pm 293.52 \mathrm{ng} / \mathrm{L}$ ). Serum CRP levels of $50 \% \mathrm{VO}_{2}$ max and $75 \% \mathrm{VO}_{2}$ max sessions $(1.19 \pm 0.50 ; 1.07 \pm 0.52 \mathrm{mg} / \mathrm{L})$ were significantly higher than the rest condition $(0.74 \pm 0.35 \mathrm{mg} / \mathrm{L})$. There were significant differences in serum $\mathrm{IL}-10$ levels of rest condition and $50 \% \mathrm{VO}_{2}$ max; $50 \% \mathrm{VO}_{2}$ max, and $100 \% \mathrm{VO}_{2}$ max sessions $(328.09 \pm 128.87 ; 446.36 \pm 142.84 ; 347.44 \pm 135.69$; $324.88 \pm 168.06 \mathrm{pg} / \mathrm{mL}$ ). Serum HIF-1 a levels were significantly higher in $75 \% \mathrm{VO} 2$ max session compared to rest $(1.26 \pm 0.16 ; 1.08 \pm 0.19 \mathrm{ng} / \mathrm{mL})(P<0.05$ for all comparisons).

Conclusions: Both inflammatory and anti-inflammatory pathway is induced on different exercise intensities. Exercise protocols performed until exhaustion may lead to activation of inflammatory pathways and hypoxia-induced damage.

Keywords: Anti-inflammatory cytokine, Exercise, Health, Hypoxia, Pro-inflammatory cytokine

*Correspondence: drbaygutalp@gmail.com

${ }^{1}$ Department of Physical Medicine and Rehabilitation, Ataturk University Faculty of Medicine, Erzurum, Turkey

Full list of author information is available at the end of the article

\section{Background}

The optimal exercise type and intensity should be carefully determined, particularly in acute exercise protocols. While moderate exercise generally improves immune function, excessive amounts of prolonged, high-intensity original author(s) and the source, provide a link to the Creative Commons licence, and indicate if changes were made. The images or other third party material in this article are included in the article's Creative Commons licence, unless indicated otherwise in a credit line to the material. If material is not included in the article's Creative Commons licence and your intended use is not permitted by statutory regulation or exceeds the permitted use, you will need to obtain permission directly from the copyright holder. To view a copy of this licence, visit http://creativecommons.org/licenses/by/4.0/. The Creative Commons Public Domain Dedication waiver (http://creativeco mmons.org/publicdomain/zero/1.0/) applies to the data made available in this article, unless otherwise stated in a credit line to the data. 
exercise may lead to impairments in immune function [1]. There are promising results from comparison studies demonstrating the equality or superiority of highintensity intermittent training (HIIT) programs over low-intensity regular exercise programs based on cardiorespiratory and metabolic parameters [2-4]. For this reason, there is a growing interest in the studies with high-intensity intermittent training protocols since this training type is considered helpful for people who cannot exercise regularly, and HIIT protocols are time efficient $[5,6]$.

Exercise and intense training affect hormonal release, creating adaptive responses that will facilitate the organism to cope with exercise stress [7]. Further, exercise may be considered as a medicine against metabolic syndrome. The inflammatory response is the body's reaction and defence against homeostasis disorders, particularly infection and injury [8]. It has long been recognized that exercise is related to anti-inflammatory pathways $[9,10]$. However, the pro-inflammatory pathway may be activated, in eccentric exercise protocols $[11,12]$. Therefore, optimal exercise protocol should be used for athletes and sedentary people to improve outcomes and prevent musculoskeletal damages, cardiovascular, neurological, and endocrinological side effects $[13,14]$.

The release of pro-inflammatory cytokines and antiinflammatory cytokines into the circulation in response to exercise varies according to exercise type, duration, and intensity $[1,13]$.

Tumor necrosis factor alpha (TNF- $\alpha)$ is an essential mediator of the acute inflammatory response [15]. Interleukin-10 (IL-10) is one of the most important antiinflammatory cytokines [5]. Increased serum TNF- $\alpha$ and C-reactive protein (CRP) levels and decreased IL-10 levels can be regarded as typical signs of a pro-inflammatory state [9]. In addition, the IL-10/TNF- $\alpha$ ratio can be used as an indicator of the beneficial effects of exercise [16]. Many studies investigate the inflammatory response in exercise [11, 12] or training sessions $[9,17]$, and the results are inconsistent. These inconsistencies may arise from various exercise or training protocols (type, duration and intensity), blood sampling timing, lack of control group, small sample sizes, ethnicity and biological variations.

CRP is the main acute phase protein in tissue damage and other inflammatory conditions and is a sensitive and objective marker [18]. As a result of a systematic review on CRP, it was found that in trained athletes, when a single exercise protocol was applied, CRP temporarily increased as the acute phase response after exercise. In contrast, those who did higher levels of physical activity in longitudinal studies had lower CRP levels. In this context, although physical activity has been found to raise the CRP level acutely, it has been found that chronically physical activity reduces CRP levels [19].

Hypoxia is one of the stress factors that can promote the inflammation process, including pro-inflammatory and anti-inflammatory pathways. Also inflammatory tissues usually become hypoxic [20]. Hypoxia or decreased oxygen levels result in many changes at the cellular level, including mitochondrial biogenesis and angiogenesis in rest [21, 22] and exercise conditions [23]. Peroxisome proliferator-activated receptor-gamma coactivator 1 alpha (PGC-1 $\alpha$ ), hypoxia-inducible factor-1 alpha (HIF-1 $\alpha)$ and vascular endotheial growth factor (VEGF) play key roles in these adaptation mechanisms. HIF- $1 \alpha$ is a hypoxia-induced transcription factor that transcribes more than 100 enzymes and proteins involved in cellular responses caused by hypoxia [24].

There is a relationship between the body's response to inflammation or exercise stress and its response to hypoxia, and in both cases, the hypoxia-inducible factor1a (HIF-1a) signaling pathway can be induced [25]. It is known that both exercise and hypoxia can alter mRNA expression and protein release of pro-and anti-inflammatory cytokines, activate lymphocytes, alter chemokine receptors, or induce other signaling pathways of the hypoxic inflammatory response $[26,27]$.

This study was conducted in a low altitude $(1850 \mathrm{~m})$ city [28], which is the highest city of Turkey. People living in altitudes higher than sea level have reduced hypoxic ventilatory response, decreased pulmonary hypertension under hypoxia, increased heart rate, and improved peripheral oxygen saturation [29]. The fact that the hypoxia and inflammatory responses were evaluated on different exercise intensities and that the study was conducted in a low altitude region is prominent in our study. For these reasons, in this study, the acute effects of exercise intensity on hypoxia and inflammatory responses in an amateur athlete group living in a low altitude region were investigated. The combined effects of hypoxia marker and exercise on inflammatory pathways were assessed.

\section{Methods}

Twenty-three amateur male athletes (soccer) living at low altitude $(1850 \mathrm{~m})$, training $2 \mathrm{~h} /$ day, 5 days/week, were included in this study. Inclusion criteria were; to be an amateur athlete between the ages of 18-22, male gender, living in this location for at least 5 years, volunteering to participate in research being healthy and not having a chronic or acute illness. Exclusion criteria were; having any chronic disease, using any medication or stimulants, smoking and alcohol use, having limitation of movement due to injury for any reason. Twenty-three 
Table 1 Demographical characteristics of athletes

\begin{tabular}{llr}
\hline & \multicolumn{2}{l}{ Male athletes $\mathbf{( n = 2 3 )}$} \\
\cline { 2 - 3 } & Mean \pm SD & \multicolumn{1}{c}{$\mathbf{9 5 \%} \mathbf{C l}$} \\
\hline Age (year) & $20.12 \pm 0.15$ & $13.51-26.49$ \\
$\mathrm{BMI}\left(\mathrm{kg} / \mathrm{m}^{2}\right)$ & $23.44 \pm 1.29$ & $22.44-23.56$ \\
$\mathrm{BFP}$ & $15.19 \pm 7.19$ & $11.89-18.11$ \\
Sports age (year) & $10.21 \pm 2.31$ & $9.00-11.00$ \\
$\mathrm{VO}_{2}$ max $\left(\mathrm{mL} \mathrm{kg} \mathrm{min}{ }^{-1}\right)$ & $54.15 \pm 6.14$ & $51.34-56.66$ \\
\hline
\end{tabular}

SD: standart deviation, Cl: confident interval, BMI: body mass index, BFP: body fat percentage, $\mathrm{VO}_{2}$ max: maximal oxygen consumption

people who met the inclusion criteria were included to the study. Demographical characteristics of athletes are given in Table 1. Athletes were evaluated at rest and at three different exercise intensities: 30 min of exercise on a bicycle ergometer at $50 \%$ of the predetermined maximal oxygen consumption capacity $\left(\mathrm{VO}_{2} \max \right)$ values, $75 \%$ of the predetermined $\mathrm{VO}_{2}$ max and exercise at $100 \% \mathrm{VO}_{2}$ max-until the individual is exhausted. Venous blood samples were taken at rest state (1st session) and immediately after each exercise sessions (2nd, 3rd and 4th sessions).

\section{Ethical Issues}

The informed consent form was obtained from all participants, and they were enlightened with all matters related to the study. The study was approved by the Clinical Research Ethics Committee of Ataturk University Faculty of Medicine (27.05.2021).

\section{Study design}

The study design is summarized in Fig. 1. 2nd session can be defined as mild intensity exercise (50\% for $30 \mathrm{~min}$ ), 3rd session as moderate-intensity exercise $(75 \%$ for $30 \mathrm{~min})$ and 4 th session as high-intensity exercise $(100 \%$ to exhaustion).

Exercise sessions were carried out at one-week intervals to prevent physiological adaptation.

\section{Data collection \\ Demographical characteristics and height measurement}

The athletes' ages in the study were recorded based on their identity information, and the sports ages based on their declarations. The height of the athletes was measured with a mechanical measuring rod (Seca 216, Medisave UK Co., UK).

\section{Body composition measurement}

Body composition parameters (weight and body fat percentage) were measured with the BOD POD body composition tracking system (Cosmed, USA). Body mass index (BMI) was calculated with the following formula: $\mathrm{BMI}=$ weight $/$ height $^{2}\left(\mathrm{~kg} / \mathrm{m}^{2}\right)$.

\section{Maximal oxygen consumption capacity $\left(\mathrm{VO}_{2} \mathrm{max}\right)$ measurement (pre-test - incremental cycle exercise test)} The participants were subjected to a maximal exercise test with an exercise protocol with increasing intensity following the test completion criteria used in the bicycle

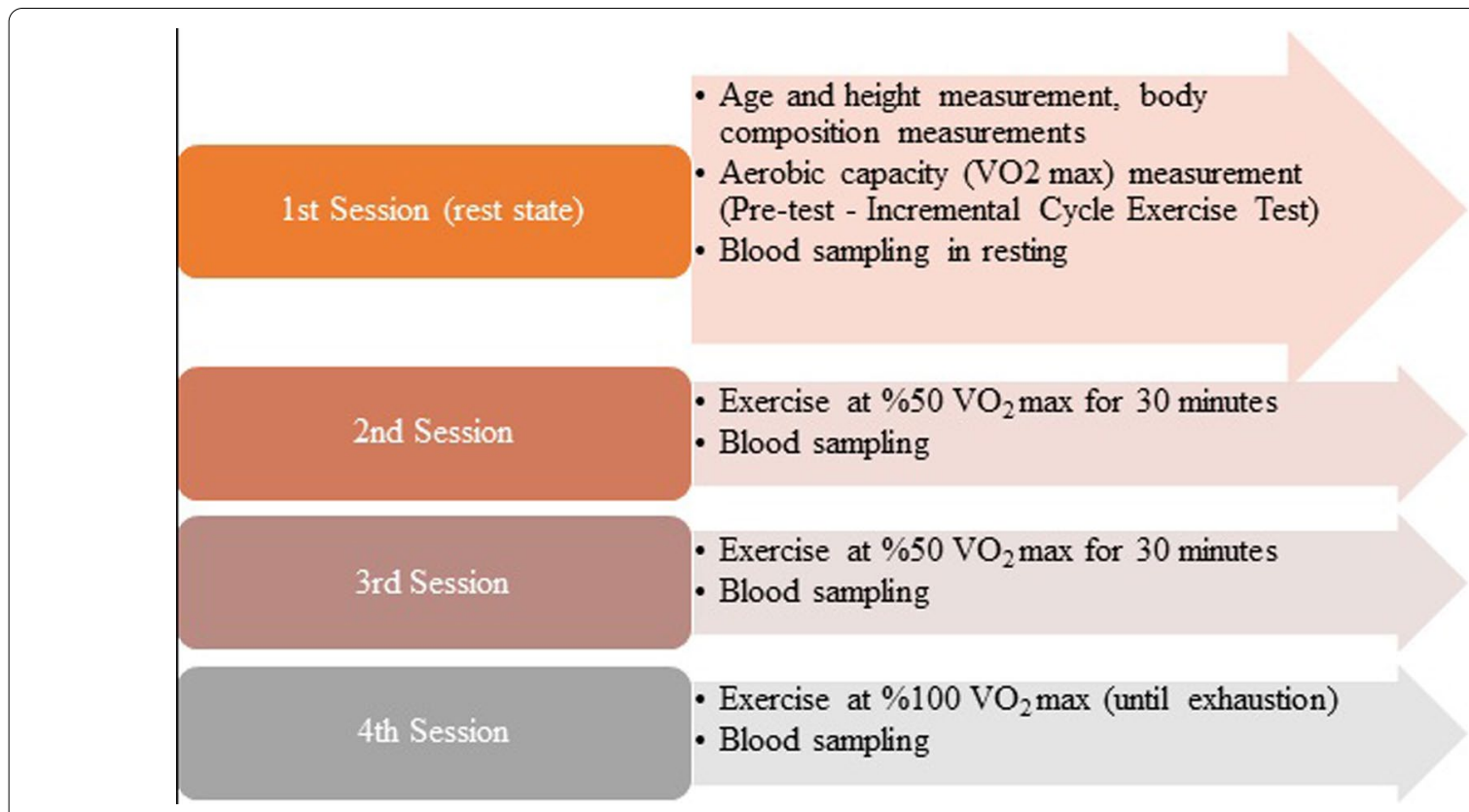

Fig. 1 Study design 
ergometer protocols used for maximal oxygen consumption capacity and power measurements.

Participants first cycled on the bicycle ergometer for 5 min (50-60 RPM) to warm up. Then, the warming was completed by stretching for $2 \mathrm{~min}$. As soon as the participant is fully ready, the test is started with the start command and the continuously increasing load test is applied. The participant started the test at 60 revolutions per minute and by pedaling at 150 watts. Then, 30 watts were increased every $2 \mathrm{~min}$, and the trial continued until the test pedal speed fell below 50 revolutions per minute or the subject could not continue anymore. The Rating of Perceived Exertion (RPE) was defined with the Borg scale to determine the $\mathrm{VO}_{2}$ max of the participants [30]. Participant-reported Borg scale scores were used at each load-increasing phase of the exercise test in the first session they visited the laboratory and immediately after each session.

The observation of three of the criteria simultaneously was accepted to indicate that the maximal oxygen use capacity was reached, then the test was terminated. The criteria were; reporting a Borg scale score of 20 by the participant, the oxygen consumption does not increase despite the increase in workload, the ratio of carbon dioxide production to oxygen consumption RER (respiratory exchange ratio) reaches 1.15 and above, the heart rate is $85 \%$ and above the maximum number of heart rates, the increase in the number of heart rates despite the increasing workload [31]. In the gas analysis, minute ventilation $(\mathrm{VE})$, oxygen volume per minute $\left(\mathrm{VO}_{2}\right)$, produced carbon dioxide volume $\left(\mathrm{VCO}_{2}\right)$ per minute were directly measured and recorded. At the same time, the heart rate (HRmax) at which the athletes reached the maximal oxygen use and the perceived difficulty values at each step of increase were also recorded. Before the measurement sessions, the Cosmed K5 oxygen analyzer was calibrated with high-grade calibration gases provided by the manufacturers. Gas was pumped from the flow meters with a 3-L calibration syringe following the manufacturer's recommendations and heated for a minimum of $15 \mathrm{~min}$. Mask size was determined individually before the first test, and measurements were taken with the same size in subsequent sessions.

\section{Exercise protocols}

All of the test protocols were carried out in our university's Sports performance laboratory and measurement center. Athletes were not allowed to perform vigorous exercise, using drugs, caffeine, alcohol and performanceenhancing ergogenic supplements from $48 \mathrm{~h}$ before exercise protocols. Before starting exercise protocols (pre-test), the participants' maximal oxygen consumption values $\left(\mathrm{VO}_{2} \max \right)$ were determined using the oxygen analyzer K5 (Cosmed, USA) as a pre-test with the gradually increasing load exercise test on the bicycle ergometer. Participants were required to cycle continuously for $30 \mathrm{~min}$ on a bicycle ergometer at $50 \%$ and $75 \%$ of the predetermined maximal oxygen consumption capacity values.

Finally the participants were required to cycle at $100 \% \mathrm{VO}_{2} \max$ until exhaustion.The term $100 \% \mathrm{VO} 2$ max defines the situation when the participant reaches exhaustion during exercise. [32]. The mean time to exhaustion of athletes was $16.35 \pm 3.38 \mathrm{~min}$. Venous blood samples were taken immediately after each session. All measurements were taken at the same time of day (morning time).

\section{Biochemical analysis}

$5 \mathrm{~mL}$ of venous blood samples were taken from each athlete. After the serum was obtained, the samples were aliquoted and stored at $-80 \mathrm{C}^{\circ}$ until analysis. Serum CRP, TNF- $\alpha$, interleukin-10 and HIF- $1 \alpha$ levels in all samples were analyzed by ELISA method with commercial kits (Bioassay Technology Laboratory-BT Lab, China produced all kits). Samples were collected once and measured duplicated.

\section{Sample size calculation}

The minimum number of patients required for the study was calculated in the G Power sample calculation program (version 3.1.9.4) at the level of Type I error $(\alpha)$ 0.05) and Type II error (1- $\beta$ ) 0.95, with an effect size (Cohen's f) of 0.4 (large) for a priori calculation of ANOVA test for 4 repeated groups. Accordingly, the minimum number of samples was determined as 16 . We included 23 participants to the study, in order to prevent a limitation caused by small sample size.

\section{Statistical analyses}

Statistical analysis was performed in SPSS 23.0 package program. Kolmogorov-Smirnov test was used to determine the normality of data. Descriptive statistical analysis, repeated measures ANOVA test, and Pearson correlation analysis were performed. Data were presented as mean $\pm \mathrm{SD}$ (standard deviation). Kolmogorov-Smirnov test revealed that data were distributed normally, and repeated measures ANOVA test was used to compare biochemical values of different sessions. Values of $P<0.05$ at a $95 \%$ confidence interval were considered statistically significant. Eta-squared value $\left(\eta^{2}\right)$ was used to determine effect sizes within the ANOVA calculation. $\eta^{2}$ values of $0.01,0.06$, and 0.14 were interpreted as "small", "medium" and "large" effect sizes, respectively. 
Table 2 Biochemical values of athletes

\begin{tabular}{|c|c|c|c|c|c|}
\hline & Rest state & $50 \% \mathrm{VO}_{2} \max$ & $75 \% \mathrm{VO}_{2} \max$ & $100 \% \mathrm{VO}_{2} \max$ & $n^{2}$ \\
\hline IL-10 (pg/mL) & $328.09 \pm 128.87^{a}$ & $446.36 \pm 142.84^{d}$ & $347.44 \pm 135.69$ & $324.88 \pm 168.06$ & 0.546 \\
\hline TNF-a (ng/L) & $331.65 \pm 293.52^{b, c}$ & $395.59 \pm 319.82$ & $472.70 \pm 365.21$ & $489.03 \pm 368.37$ & 0.309 \\
\hline IL-10/TNF-a & $1.63 \pm 1.20^{c}$ & $1.49 \pm 0.93^{d}$ & $1.34 \pm 0.97$ & $0.99 \pm 0.67$ & 0.566 \\
\hline $\mathrm{CRP}(\mathrm{mg} / \mathrm{L})$ & $0.74 \pm 0.35^{a, b}$ & $1.19 \pm 0.50$ & $1.07 \pm 0.52$ & $0.97 \pm 0.55$ & 0.773 \\
\hline $\mathrm{HIF-1a}(\mathrm{ng} / \mathrm{mL})$ & $1.08 \pm 0.19^{b}$ & $1.12 \pm 0.32$ & $1.26 \pm 0.16$ & $1.18 \pm 0.21$ & 0.453 \\
\hline
\end{tabular}

$\eta^{2}$ : Eta-squared value

a,b,c,d Show repeated measures ANOVA Bonferroni post-hoc test $P$ values

${ }^{\text {a }}$ Significant difference $(P<0.05)$ between rest state and $50 \% \mathrm{VO}_{2}$ max session

${ }^{\mathrm{b}}$ Significant difference $(P<0.05)$ between rest state and $75 \% \mathrm{VO}_{2}$ max session

c Significant difference $(P<0.05)$ between rest state and $100 \% \mathrm{VO}_{2}$ max session

${ }^{\mathrm{d}}$ Significant difference $(P<0.05)$ between $50 \% \mathrm{VO}_{2}$ and $100 \% \mathrm{VO}_{2}$ max sessions

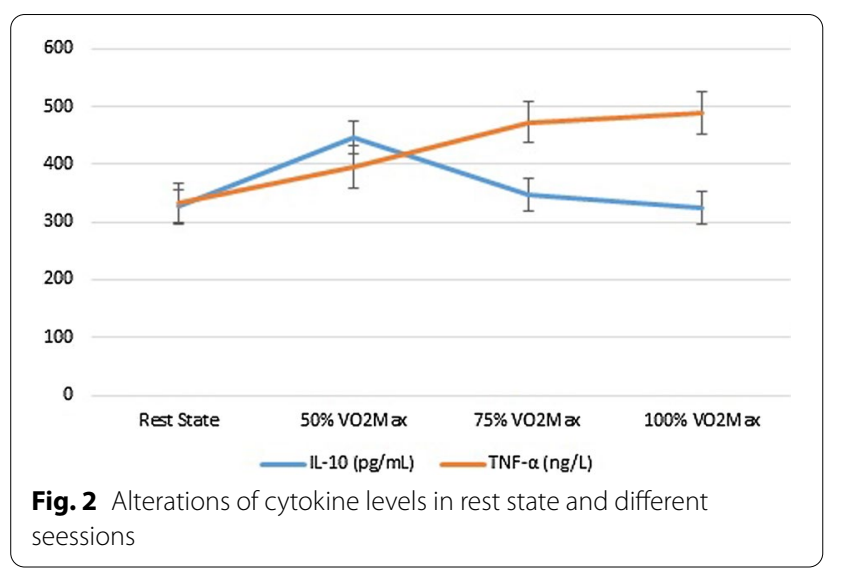

\section{Results}

Serum IL-10, TNF- $\alpha$, CRP and HIF- $1 \alpha$ values obtained at rest conditions and different exercise sessions are given in Table 2. Additionally, IL-10/TNF- $\alpha$ ratio was used as a positive predictor of exercise and presented the results in Table 2 . Results show that IL-10/TNF- $\alpha$ ratio was decreased in $100 \% \mathrm{VO}_{2}$ max session compared to both rest and $50 \% \mathrm{VO}_{2}$ sessions $(P=0.008$ and $P=0.041$, respectively).

The pairwise comparisons of biochemical values between rest state and different sessions were performed with the repeated measures ANOVA test, and the results are summarized in Table 2. Results showed significant differences in serum TNF- $\alpha$ levels between rest condition and $75 \% \mathrm{VO}_{2}$ max; rest and $100 \% \mathrm{VO}_{2}$ $\max$ session. There were significant differences in serum CRP levels between rest and $50 \% \mathrm{VO}_{2}$ max; rest and $75 \% \mathrm{VO}_{2} \max$ sessions. There were significant differences in serum IL-10 levels between rest and 50\% $\mathrm{VO}_{2} \max , 50 \% \mathrm{VO}_{2}$ max, and $100 \% \mathrm{VO}_{2}$ max sessions. There were significant differences in serum HIF- $1 \alpha$ levels between rest and $75 \% \mathrm{VO}_{2}$ max session $(P<0.05$ for all comparisons). All other comparisons were not statistically significant $(P>0.05$ for all other pairs). The alterations in pro-inflammatory and anti-inflammatory pathways are shown in Fig. 2 with the results of IL-10 and TNF- $\alpha$.

Pearson correlation analyses were performed to evaluate the relationships between biochemical parameters in rest conditions and each exercise session. Results showed a high negative correlation between serum HIF- $1 \alpha$ and TNF- $\alpha$ levels on $50 \% \mathrm{VO}_{2}$ max session ( $\mathrm{r}:-0.634$, $P=0.003)$. There was a moderate positive correlation between serum HIF-1 $\alpha$ and IL-10 levels at $75 \% \mathrm{VO}_{2} \max$ session ( $\mathrm{r}$ : 0.593, $P=0.006$ ) (Fig. 3).

Correlation analysis showed that serum HIF- $1 \alpha$ levels were negatively related to serum TNF- $\alpha$ levels and positively related to serum IL-10 levels. Changes in HIF-1 $\alpha$ concentrations during exercise may have negatively affected the pro-inflammatory pathway and positively affected the anti-inflammatory pathway as a protection mechanism.

\section{Discussion}

In this study, the acute effects of different exercise intensities on serum IL-10, TNF- $\alpha$, CRP and HIF-1 $\alpha$ levels were reported for the first time. Additionally, the study was conducted in a low altitude $(1850 \mathrm{~m})$ city. Exercise practice until exhaustion caused significant pro-inflammatory effects (demonstrated with TNF- $\alpha$ ) and the optimal IL-10 response on $50 \% \mathrm{VO}_{2}$ max decreased to nearly baseline level as the exercise intensity reached to $100 \% \mathrm{VO}_{2}$ max. Thus, we can suggest that exercise intensity should not reach to exhaustion due to there was no improvement in the anti-inflammatory marker IL-10 and there was an increment in the pro-inflammatory marker TNF- $\alpha$ with the potential increase in inflammation. There is a high altitude camping center for athletes in our 

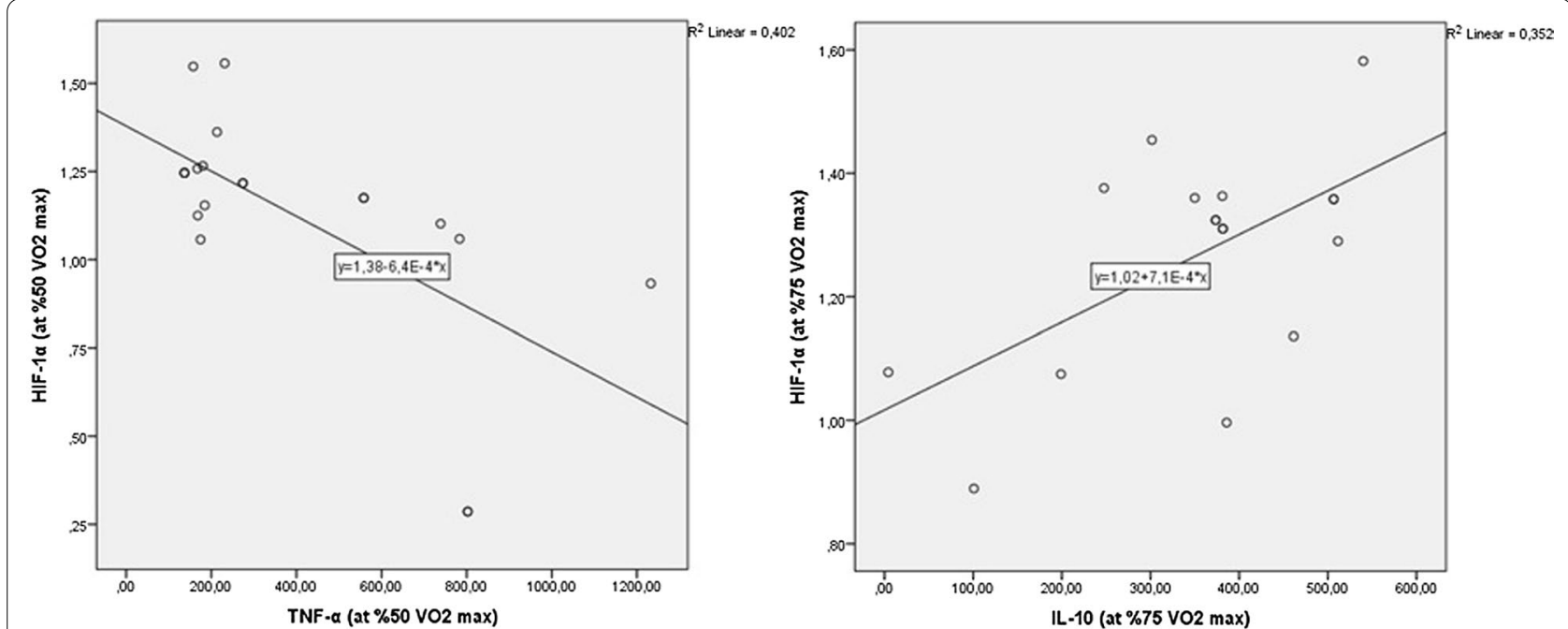

Fig. 3 Scatter-dot graphs of Pearson correlation analysis. A Significant negative correlation between HIF-1 a and TNF- $a$ at $50 \% \mathrm{VO}_{2}$ max session; $(\mathrm{r}$ : $-0.634, P=0.003)$. B Significant positive correlation between HIF- $1 \mathrm{a}$ and IL-10 at $75 \% \mathrm{VO}_{2}$ max session $(r: 0.593, P=0.006)$.

city, and athletes from all over the country use this center. For this reason, the study has regional and national added value.

Several studies have investigated the responses of proinflammatory cytokines, inflammatory cytokines and inflammatory markers to different exercise intensities and modalities, and these studies report distinct results $[11,13,16,17,33,34]$. The conflicting results from previous literature may arise from differences in exercise intensities, exercise modalities, VO2 max capacities, the timing of blood sampling and biological variations.

In a study conducted with 20 soccer players with a mean age of $25.75 \pm 3.99$ years, participants were subjected to a single bout high high-intensity interval training and plasma IL-6, IL-1 and TNF- $\alpha$ levels determined before and immediately after training. There was a significant increase in plasma interleukin-6 levels after exercise; however, no significant increase in IL-1 and TNF- $\alpha$ levels showing an anti-inflammatory condition might occur through high-intensity interval training sessions [34]. The training protocol of this study and the exercise protocol of the current research is different, and it's known that metabolic changes may occur differently in training and exercise. However, the type of sports and age of the participants in the two studies are similar. We observed increments in both anti-inflammatory and pro-inflammatory cytokines; anti-inflammatory marker (IL-10) was increased at $50 \% \mathrm{VO}_{2}$ session, and proinflammatory marker (TNF- $\alpha$ ) was increased $75 \% \mathrm{VO}_{2}$ and $100 \% \mathrm{VO}_{2}$ sessions, and inflammatory (CRP) marker was increased at $50 \% \mathrm{VO}_{2}$ and $75 \% \mathrm{VO}_{2}$ sessions. We used high-intensity exercises, and researchers have used high-intensity interval training (HIT). We could not show the anti-inflammatory effects of high intensity exercise in our study, although other researchers have shown the anti-inflammatory effects in their study using highintensity interval training (HIIT).

The TNF- $\alpha$ level is decreased by moderate exercise (exercise intensity HRmax 60-70\%) [33], and mRNA expression of TNF- $\alpha$ is known to be slightly elevated in skeletal muscle by endurance exercise [35]. In the previous study, a gradient increment was observed in serum TNF- $\alpha$ levels as exercise intensity increases. The highest TNF- $\alpha$ response to exercise was found at $100 \% \mathrm{VO}_{2}$ max session when the athlete presents his maximum endurance.

A systematic review including 18 articles investigating the effects of moderate and intense exercise on inflammatory response concluded that intense long exercise protocols might activate pro-inflammatory pathways. Instead of this, moderate or high-intensity intermittent exercise protocols with suitable rest conditions may be preferred [1]. We are in line with this conclusion since we observed an inflammatory profile by determining high TNF- $\alpha$ and CRP levels in $75 \% \mathrm{VO}_{2}$ max and $100 \% \mathrm{VO}_{2}$ max sessions and optimal IL-10 concentration at $50 \% \mathrm{VO} 2 \max$ session. Although there is evidence of minimal pro-inflammatory cytokine response and high anti-inflammatory cytokine release from a study conducted on athletes competing in an ironman triathlon race [36], it should be considered that triathlon race is a type of ultra-endurance exercise. We suggest IL-10 levels were not increased as expected at $75 \% \mathrm{VO} 2$ max and $100 \% \mathrm{VO} 2$ max exercise 
intensities because of pro-inflammatory effects. CRP level partially supported this suggestion, being significantly higher in the $75 \% \mathrm{VO} 2$ max session than the rest state. Among studies investigating the impact of exercise on CRP release, most of them reveal increased CRP levels immediately after moderate [37] and intense exercise [38]. Yet, a study reports no effect of exercise modality on acute CRP response [39]. As determined the highest CRP value in $75 \% \mathrm{VO} 2$ max session and elevated values in $75 \% \mathrm{VO} 2$ max session compared to rest state in the present study, we can conclude that CRP partly acts together with the pro-inflammatory pathways. However, we could not determine any significant correlation between CRP and TNF- $\alpha$. Although we determined optimal IL-10 levels and relatively low TNF- $\alpha$ levels (compared to $75 \%$ VO2 max and 100\% $\mathrm{VO} 2)$ at $50 \% \mathrm{VO} 2$ max session, we can not recommend using this intensity to athletes since this intensity is not related to training for fitness improvements/adaptations, and as well as for soccer as the participants in the current investigation were indeed soccer players. Further, $50 \%$ intensity will not be adequate to stress the body to induce an adaptation. Acute exercise sessions lead to a complex cascade of inflammatory and proinflammatory pathways [40-42]. We are in line with this conclusion with altered TNF- $\alpha$, IL-10, and CRP levels among sessions.

Considering the current study results and related studies, we can speculate that moderate intensity exercise with durations longer than $30 \mathrm{~min}$ (providing higher endurance than the present study) may be beneficial to prevent/reduce pro-inflammatory response.

It is known that disease-induced hypoxia is closely related to the activation of inflammatory pathways, but less information is available about the effects of exerciseinduced hypoxia on inflammation. There is a relationship between hypoxia and the release of pro-inflammatory cytokines. Moreover, HIF- $1 \alpha$ is important in controlling excessive inflammation [23]. Also, hypoxia, inflammation, and exercise can induce the HIF- $1 \alpha$ pathway. It was shown that skeletal muscle HIF-1 protein content increased by $120 \%$ with hypoxia, and HIF- $1 \alpha$ released in response to hypoxia was triggered by the effect of exercise [43]. In the present study, serum HIF-1 $\alpha$ levels were significantly increased in $75 \% \mathrm{VO} 2$ max session compared to rest state in a high-lander athlete population living in this location for at least 5 years.

At hypoxia conditions in the exercising person, the inflammatory pathways are regulated differently. The hypoxic and exercise stimuli are stronger in vivo than the hypoxic or inflammatory stimuli isolated in vitro [24].

Of note, when considering HIF- $1 \alpha$ results, it should be kept in mind that high interindividual variability may be seen in the expression of HIF and its target genes in response to inflammatory or hypoxic stimuli, and single nucleotide polymorphisms (SNPs) are thought to be involved in these changes [25].

There is a relation between hypoxia and inflammation. Hypoxia can induce inflammation, and inflamed tissues may become hypoxic [20]. Limited studies investigating the effects of exercise on inflammatory pathways in hypoxic conditions revealed no changes in pro-inflammatory cytokines, and increases in anti-inflammatory cytokines, indicating the positive effects of exercising in hypoxic conditions.

The triple relation of exercise, inflammatory pathways, and oxygen consumption in a low altitude location were investigated in a previous study. HIF-1 $\alpha$ response is maximum on $75 \% \mathrm{VO}_{2}$ max session and decreases from this maximum value on exhaustion. This result follows the finding that high-intensity exercise in hypoxia can further induce HIF-1 $\alpha$ expression [43]. It is well known that high-lander athletes show better exercise performance and greater $\mathrm{VO}_{2}$ max capacity than sea-landers since athletes have adapted to hypoxia, and maybe some have a genetic basis, thanks to the effect of altitude [44, 45].

Although there is no agreement to define the term "high-intensity", it widely refers to exercise intensity higher than $75 \% \mathrm{VO}_{2} \max$ [23]. A speculative model suggests that HIF- $1 \alpha$ and PGC- $1 \alpha$ act as mediators in the adaptation of skeletal muscle. The mediators lead to upregulation of mitochondrial biogenesis, angiogenesis via activation of VEGF and a shift in the skeletal muscle fibre type. Both high-intensity exercise/training and hypoxia lead to this mechanism to upregulate skeletal muscle adaptation [23].

We observed the optimum HIF-1 $\alpha$ response in a $75 \%$ VO2 max session in the present study.

HIF-1 $\alpha$ response did not increase when the exercise intensity was reached from $75 \% \mathrm{VO}_{2}$ max to $100 \% \mathrm{VO}_{2}$ $\max$ in the present study. We attribute this because the athletes have developed a physiological adaptation to hypoxia thanks to living at low altitudes. Correlation analyses revealed a high negative correlation between serum HIF- $1 \alpha$ and TNF- $\alpha$ levels on $50 \% \mathrm{VO}_{2}$ max session ( $\mathrm{r}:-0.634, P=0.003)$ and a moderate positive correlation between serum HIF-1 $\alpha$ and IL-10 levels at $75 \%$ $\mathrm{VO}_{2}$ max session ( $\mathrm{r}: 0.593, P=0.006$ ). Results suggest that increased HIF- $1 \alpha$ levels reflect the pro-inflammatory condition in $50 \% \mathrm{VO}_{2}$ max session and the anti-inflammatory condition in $75 \% \mathrm{VO}_{2}$ max session. We determined maximum TNF- $\alpha$ response and similar IL-10 response compared to baseline in $100 \% \mathrm{VO}_{2}$ max session. We can conclude that the pro-inflammatory effects of hypoxia and anti-inflammatory effects of the exercise 
was probably due to activating the release of anti-inflammatory cytokines and downregulating toll-like receptor (TLR) signalling [23].

Studies with different exercise protocols have shown that high-intensity exercise (above $75 \%$ of the peak power output) provides similar or even higher benefits than a low-intensity continuous exercise in improving heart health, respiratory health, and metabolic health. Increases in peak power outputs during exercise result in increased metabolic responses, compromising skeletal muscle integrity, which can cause early onset of fatigue and exhaustion. Therefore, the selection of exercise intensity should be made carefully to avoid undesirable consequences. Taken together, TNF- $\alpha$, IL-10, CRP, and HIF- $1 \alpha$ results, we again suggest that exercise intensity should not reach to exhaustion. Despite its originality, the current study has a limitation. It would be better ELISA results should be supported with western blotting analysis and mRNA expression levels of proteins.

\section{Conclusions}

There is a tight connection between hypoxia and inflammation, and studies investigating the effects of exercise intensity in hypoxic and inflammatory pathways are limited. There is no available study in any athletic population reporting the acute changes on serum IL-10, TNF$\alpha$, CRP and HIF- $1 \alpha$ levels induced by different exercise intensities. We noted that both inflammatory and antiinflammatory pathway is induced on different exercise intensities. As the need for oxygen increases, the inflammatory pathway (by TNF- $\alpha$ and CRP) is induced, and anti-inflammatory cytokine IL-10 reaches optimal value on exercise intensity of $50 \% \mathrm{VO}_{2}$ max. Exercise regimens (not reached to exhaustion) are recommended to prevent inflammation, hypoxia-induced damage, and existing muscle damage progression if any. Further studies on different athlete groups should be conducted to determine the optimum exercise intensity and maximum benefit.

\begin{abstract}
Abbreviations
$\mathrm{VO}_{2}$ max: Maximal oxygen consumption values; TNF-a: Tumor necrosis factor alpha; IL-10: Interleukin-10; CRP: C-reactive protein; HIF-1 a: Hypoxia inducible factor-1 alpha.
\end{abstract}

\section{Acknowledgements}

The authors would like to thank the athletes that took part in this study. The authors would like to thank to Prof. Mostafa Abdelaty HASSIBELNABY for his scientific contribution to the study.

\section{Authors' contributions}

FB: concept, design, inspection of all participants, writing article, critical review of the article; YB: performing exercise protocol, writing article, critical review of the article; $\mathrm{MO}$ : performing exercise protocol, writing article, critical review of the article; MK: critical review of the article; NKB: biochemical analysis, statistical analysis, critical review of the article; GA: determining exercise protocol, critical review of the article. All authors read and approved the final manuscript.

Funding

None.

Availability of data and materials

The datasets used and/or analyzed during the current study are available from the corresponding author on reasonable request.

\section{Declarations}

Ethics approval and consent to participate

The informed consent form was obtained from all participants, and they were enlightened with all matters related to the study. The study was approved by the Clinical Research Ethics Committee of Ataturk University Faculty of Medicine (27.05.2021)

\section{Consent for publication}

Not applicable.

\section{Competing interests}

Not applicable.

\section{Author details}

${ }^{1}$ Department of Physical Medicine and Rehabilitation, Ataturk University Faculty of Medicine, Erzurum, Turkey. ${ }^{2}$ Department of Physical Education and Sports, Erzurum Technical University Faculty of Sport Sciences, Erzurum, Turkey. ${ }^{3}$ Department of Physical Education and Sports, Ataturk University Kazım Karabekir Education Faculty, Erzurum, Turkey. ${ }^{4}$ Department of Sports Health Sciences, Ankara University Faculty of Sport Sciences, Ankara, Turkey. ${ }^{5}$ Department of Biochemistry, Ataturk University Faculty of Pharmacy, Erzurum, Turkey. ${ }^{6}$ Department of Recreation, Ataturk University Faculty of Sport Sciences, Erzurum, Turkey.

Received: 25 June 2021 Accepted: 15 November 2021

Published online: 22 November 2021

\section{References}

1. Cerqueira É, Marinho DA, Neiva HP, Lourenço O. Inflammatory effects of high and moderate intensity exercise - a systematic review. Front Physiol. 2019;10:1550

2. Beauchamp MK, Nonoyama M, Goldstein RS, Hill K, Dolmage TE, Mathur S, et al. Interval versus continuous training in individuals with chronic obstructive pulmonary disease-a systematic review. Thorax. 2010:65(2):157-64.

3. Rognmo Ø, Moholdt T, Bakken H, Hole T, Mølstad P, Myhr NE, et al. Cardiovascular risk of high- versus moderate-intensity aerobic exercise in coronary heart disease patients. Circulation. 2012;126(12):1436-40.

4. Nicolò A, Bazzucchi I, Haxhi J, Felici F, Sacchetti M. Comparing continuous and intermittent exercise: an "isoeffort" and "isotime" approach. PLoS ONE. 2014;9(4):e94990

5. Weston KS, Wisløff U, Coombes JS. High-intensity interval training in patients with lifestyle-induced cardiometabolic disease: a systematic review and meta-analysis. Br J Sports Med. 2014;48(16):1227-34.

6. Thum JS, Parsons G, Whittle T, Astorino TA. High-intensity interval training elicits higher enjoyment than moderate intensity continuous exercise. PLoS ONE. 2017;12(1):e0166299.

7. Gleeson M. Immune function in sport and exercise. J Appl Physiol (1985). 2007:103(2):693-9.

8. Medzhitov R. Origin and physiological roles of inflammation. Nature. 2008:454(7203):428-35.

9. Gleeson M, Bishop NC, Stensel DJ, Lindley MR, Mastana SS, Nimmo MA. The anti-inflammatory effects of exercise: mechanisms and implications for the prevention and treatment of disease. Nat Rev Immunol. 2011;11(9):607-15.

10. Pedersen BK. Anti-inflammatory effects of exercise: role in diabetes and cardiovascular disease. Eur J Clin Invest. 2017;47(8):600-11. 
11. Fielding RA, Manfredi TJ, Ding W, Fiatarone MA, Evans WJ, Cannon JG. Acute phase response in exercise. III. Neutrophil and IL-1 beta accumulation in skeletal muscle. Am J Physiol. 1993;265(1 Pt 2):R166-72.

12. O'Reilly KP, Warhol MJ, Fielding RA, Frontera WR, Meredith CN, Evans WJ. Eccentric exercise-induced muscle damage impairs muscle glycogen repletion. J Appl Physiol (1985). 1987;63(1):252-6.

13. Nobari H, Cholewa JM, Pérez-Gómez J, Castillo-Rodríguez A. Effects of 14-weeks betaine supplementation on pro-inflammatory cytokines and hematology status in professional youth soccer players during a competition season: a double blind, randomized, placebo-controlled trial. J Int Soc Sports Nutr. 2021;18(1):42.

14. Nobari H, Vahabidelshad R, Pérez-Gómez J, Ardigò LP. Variations of training workload in micro- and meso-cycles based on position in elite young soccer players: a competition season study. Front Physiol. 2021;12:668145.

15. Zelová H, Hošek J. TNF-a signalling and inflammation: interactions between old acquaintances. Inflamm Res. 2013;62(7):641-51.

16. Batista ML Jr, Rosa JC, Lopes RD, Lira FS, Martins E Jr, Yamashita AS, et al. Exercise training changes IL-10/TNF-alpha ratio in the skeletal muscle of post-Ml rats. Cytokine. 2010;49(1):102-8.

17. Ogawa K, Sanada K, Machida S, Okutsu M, Suzuki K. Resistance exercise training-induced muscle hypertrophy was associated with reduction of inflammatory markers in elderly women. Mediat Inflamm. 2010;2010:171023.

18. Tang JH, Gao DP, Zou PF. Comparison of serum PCT and CRP levels in patients infected by different pathogenic microorganisms: a systematic review and meta-analysis. Braz J Med Biol Res. 2018;51(7):e6783.

19. Kasapis C, Thompson PD. The effects of physical activity on serum C-reactive protein and inflammatory markers: a systematic review. J Am Coll Cardiol. 2005;45(10):1563-9.

20. Eltzschig HK, Carmeliet P. Hypoxia and inflammation. N Engl J Med. 2011;364(7):656-65.

21. Carmeliet $P$, Dor $Y$, Herbert JM, Fukumura D, Brusselmans $K$, Dewerchin M, et al. Role of HIF-1alpha in hypoxia-mediated apoptosis, cell proliferation and tumour angiogenesis. Nature. 1998;394(6692):485-90.

22. Semenza GL. Regulation of mammalian $\mathrm{O} 2$ homeostasis by hypoxiainducible factor 1. Annu Rev Cell Dev Biol. 1999;15:551-78.

23. Li J, Li Y, Atakan MM, Kuang J, Hu Y, Bishop DJ, et al. The molecular adaptive responses of skeletal muscle to high-intensity exercise/training and hypoxia. Antioxidants (Basel). 2020;9(8):656.

24. Kammerer T, Faihs V, Hulde N, Stangl M, Brettner F, Rehm M, et al. Hypoxic-inflammatory responses under acute hypoxia: in vitro experiments and prospective observational expedition trial. Int J Mol Sci. 2020;21(3):1034

25. Lindholm ME, Rundqvist H. Skeletal muscle hypoxia-inducible factor-1 and exercise. Exp Physiol. 2016;101(1):28-32.

26. Choi S, Chung H, Hong H, Kim SY, Kim SE, Seoh JY, et al. Inflammatory hypoxia induces syndecan-2 expression through IL-1 $\beta$-mediated FOXO3a activation in colonic epithelia. FASEB J. 2017;31(4):1516-30.

27. Dai T, Hu Y, Zheng H. Hypoxia increases expression of CXC chemokine receptor 4 via activation of PI3K/Akt leading to enhanced migration of endothelial progenitor cells. Eur Rev Med Pharmacol Sci. 2017;21(8):1820-7.

28. Bärtsch P, Saltin B, Dvorak J. Consensus statement on playing football at different altitude. Scand J Med Sci Sports. 2008;18(Suppl 1):96-9.
29. Nell HJ, Castelli LM, Bertani D, Jipson AA, Meagher SF, Melo LT, et al. The effects of hypoxia on muscle deoxygenation and recruitment in the flexor digitorum superficialis during submaximal intermittent handgrip exercise. BMC Sports Sci Med Rehabil. 2020;12:16.

30. Borg G. Perceived exertion as an indicator of somatic stress. Scand J Rehabil Med. 1970;2(2):92-8.

31. Edvardsen $E$, Hem E, Anderssen SA. End criteria for reaching maximal oxygen uptake must be strict and adjusted to sex and age: a cross-sectional study. PLoS ONE. 2014;9(1):e85276.

32. Buchfuhrer MJ, Hansen JE, Robinson TE, Sue DY, Wasserman K, Whipp BJ. Optimizing the exercise protocol for cardiopulmonary assessment. J Appl Physiol Respir Environ Exerc Physiol. 1983;55(5):1558-64.

33. Amin MN, El-Mowafy M, Mobark A, Abass N, Elgaml A. Exercise-induced downregulation of serum interleukin- 6 and tumor necrosis factor-alpha in Egyptian handball players. Saudi J Biol Sci. 2021;28(1):724-30.

34. Ghorbani P, Kordi MR, Gaeeni AA, Arbab G, Nafar MH. Changes in inflammatory factors in elite soccer players folllowing single bout high intensity interval training. Braz J Biomotricity. 2013;7(1):52-8.

35. Nieman DC, Davis JM, Henson DA, Walberg-Rankin J, Shute M, Dumke $\mathrm{CL}$, et al. Carbohydrate ingestion influences skeletal muscle cytokine mRNA and plasma cytokine levels after a 3-h run. J Appl Physiol (1985). 2003;94(5):1917-25.

36. Suzuki K, Peake J, Nosaka K, Okutsu M, Abbiss CR, Surriano R, et al. Changes in markers of muscle damage, inflammation and HSP70 after an Ironman Triathlon race. Eur J Appl Physiol. 2006;98(6):525-34.

37. Draganidis D, Chatzinikolaou A, Jamurtas AZ, Carlos Barbero J, Tsoukas D, Theodorou AS, et al. The time-frame of acute resistance exercise effects on football skill performance: the impact of exercise intensity. J Sports Sci. 2013:31(7):714-22

38. Fatouros IG, Destouni A, Margonis K, Jamurtas AZ, Vrettou C, Kouretas $D$, et al. Cell-free plasma DNA as a novel marker of aseptic inflammation severity related to exercise overtraining. Clin Chem. 2006;52(9):1820-4.

39. Mendham AE, Donges CE, Liberts EA, Duffield R. Effects of mode and intensity on the acute exercise-induced IL-6 and CRP responses in a sedentary, overweight population. Eur J Appl Physiol. 2011;111(6):1035-45.

40. Allen J, Sun Y, Woods JA. Exercise and the regulation of inflammatory responses. Prog Mol Biol Transl Sci. 2015;135:337-54.

41. Hennigar SR, McClung JP, Pasiakos SM. Nutritional interventions and the IL-6 response to exercise. Faseb j. 2017;31(9):3719-28.

42. Peake JM, Neubauer O, Walsh NP, Simpson RJ. Recovery of the immune system after exercise. J Appl Physiol (1985). 2017;122(5):1077-87.

43. Van Thienen R, Masschelein E, D'Hulst G, Thomis M, Hespel P. Twin resemblance in muscle HIF-1a responses to hypoxia and exercise. Front Physiol. 2016;7:676

44. Marconi C, Marzorati M, Cerretelli P. Work capacity of permanent residents of high altitude. High Alt Med Biol. 2006;7(2):105-15.

45. Linthorne NP. Improvement in 100-m sprint performance at an altitude of 2250 m. Sports (Basel). 2016;4(2):29.

\section{Publisher's Note}

Springer Nature remains neutral with regard to jurisdictional claims in published maps and institutional affiliations.

Ready to submit your research? Choose BMC and benefit from

- fast, convenient online submission

- thorough peer review by experienced researchers in your field

- rapid publication on acceptance

- support for research data, including large and complex data types

- gold Open Access which fosters wider collaboration and increased citations

- maximum visibility for your research: over $100 \mathrm{M}$ website views per year

At $\mathrm{BMC}$, research is always in progress.

Learn more biomedcentral.com/submissions 